\title{
Organizational Assimilation and Communication Technology Use
}

\author{
Jennifer H. Waldeck, David R. Seibold \& Andrew J. \\ Flanagin
}

Studies of organizational members' assimilation information seeking have focused on traditional channels for uncertainty reduction (e.g., face-to-face communication and traditional technologies like employee handbooks) and on the experiences of newcomers. This investigation extends organizational assimilation research by examining a variety of socialization experiences (not just those of newcomers) and by considering Advanced Communication and Information Technologies (ACITs) as an additional channel for obtaining assimilation-related information. Data from 405 employees of four organizations were utilized to explore the relationship between three channels for information seeking (face-to-face communication, traditional media, and ACIT) and perceived socialization effectiveness. Predictors of employee selection and use of ACITs also were examined, including perceptions of media richness and social presence, and user responses to their experiences using ACITs for assimilation. Results indicate that face-to-face communication is the most important predictor of assimilation effectiveness, followed by ACIT use. Least important are traditional technologies. Media characteristics, as elucidated in two prominent theories of organizational communication technology use, predicted individuals' selection and use of ACITs. Finally, a typology of members' behavioral responses to feedback regarding their ACIT use was derived, which revealed that users respond by continuing current practices, supplementing the channel, discontinuing use, expanding use, learning new uses, or by implementing a variety of these strategies.

Organizational membership can be anxiety producing even for those who are confident in their social and professional competence because so much is at stake. Although many members receive some formal training for their jobs, they find that

The authors would like to thank Michele Jackson for her helpful comments. Correspondence to: Jennifer Waldeck, Department of Communication, University of California at Santa Barbara, Santa Barbara, CA 93106-4020, USA. Email: jwaldeck516@earthlink.net 
a great deal of learning takes place on the job. They often "learn from the inside" as they interact with one another, and as they observe and practice the norms of their organizations and learn the subtle nuances of their jobs. The ability to engage in communication that reduces uncertainty can reduce stress and result in a heightened state of organizational assimilation-which ostensibly improves one's contributions to the organization, commitment to membership and tasks, and satisfaction with the organizational experience (Jablin, 2001).

This study focuses on the crucial organizational assimilation experience and the uncertainty that accompanies the assimilation process. A primary objective is to enhance the theoretical foundations of research into organizational socialization. Two tasks are undertaken. First, contemporary channels for reducing assimilationrelated uncertainty, Advanced Communication and Information Technologies (ACITs), are investigated. Most studies of organizational socialization have concentrated on traditional communication channels that support uncertainty-reducing information, including formal and informal face-to-face interactions among organizational members (cf. Hart, Miller, \& Johnson, 1998; Jablin, 1982, 1987, 2001; Kramer, Callister, \& Turban, 1995) and traditional paper documents such as memos, house newsletters, and employee handbooks (cf. Allen \& Meyer, 1990; Fedor, Buckley, \& Davis, 1997; Jablin, 1987; Lee, Ashford, Walsh, \& Mowday, 1992; Meyer \& Allen, 1988; Miller, 1997; Miller \& Jablin, 1991). Researchers' interest in technologies for assimilation-related communication has become heightened only quite recently. Consequently, although these more advanced channels were possibly used by organizational members who participated in earlier studies, the research did not focus on them.

Researchers have thoroughly explored the ways in which newcomers have been traditionally socialized-through formal and informal face-to-face interactions among newcomers and experienced employees, and via traditional paper documents such as memos and training manuals (e.g., Allen \& Meyer, 1990; Fedor et al., 1997; Jablin, 1987, 2001; Lee et al., 1992; Meyer \& Allen, 1988; Miller, 1997; Miller \& Jablin, 1991). Although these time-tested methods for organizational uncertainty reduction are still utilized by members, reliance on traditional channels alone is unlikely in contemporary organizations that enable and require communication via more advanced media. For example, email is a nearly universal medium for exchanging information, and many organizations have discovered the cost effectiveness and ease of web-based employee training delivery. Jablin (2001) underscores the importance of these developments in his recent review of organizational assimilation processes by noting that "it seems apparent that changes in communication technology ... need greater consideration in future research" (p. 745). Indeed, the use of ACITs for assimilation-related communication expands the number of opportunities available for actively seeking information that will contribute to successful organizational acculturation and assimilation. ACITs, then, warrant theoretical and empirical attention in the organizational socialization literature.

Second, this study also seeks to demonstrate the ongoing nature of organizational assimilation. Scholars have noted that organizational members must continually 
adapt to the changing norms of fluid, contemporary organizations (Jablin, 2001; Jablin \& Krone, 1987; Rice, 1983; Svenning \& Ruchinskas, 1984), especially in light of technological advances in organizational communication and rapidly changing organizational structures. However, with few exceptions (e.g., Kramer, 1993; Kramer et al., 1995; Kramer \& Noland, 1999, who examined job transfers and promotions), assimilation researchers have been slow to look beyond employees' initial weeks or months of employment. This study attempts to advance assimilation research by treating employee socialization as an ongoing process that addresses uncertainty occurring at any point in a member's tenure.

Within these contemporary theoretical parameters, this study investigates the relationship between three types of information-seeking channels (ACITs, traditional media, and face-to-face communication) and perceived socialization effectiveness. Furthermore, predictors of employee selection and use of ACITs are examined, including perceptions of media richness and social presence. Finally, user responses to feedback on their experiences with ACIT use are assessed in order to determine changes in ACIT use based on input received from the environment. This component of the study is an interesting one from both the assimilation and technology perspectives as it reveals compelling findings about ACIT use and the ongoing nature of uncertainty reduction in organizations, and consequently, assimilation.

\section{A Contemporary Perspective on Organizational Assimilation Theory}

\section{Conceptual Issues}

Nearly three decades of research indicate that organizational members have an array of important concerns regarding their ability to perform adequately and integrate successfully into their environments. For example, new organizational members (Feldman, 1976; Miller, 1997; Miller \& Jablin, 1991) and incumbents (Kramer, 1989, 1993; Kramer et al., 1995; Kramer \& Noland, 1999) have uncertainties about how to fit in, how to do their jobs, how their performance will be evaluated, how to relate to others socially, and how to select their friends at work, among others (Kramer, 1989, 1993; Kramer et al., 1995; Kramer \& Noland, 1999). Although researchers have traditionally focused on a person's job search and entry into an organization as the primary period of uncertainty (and socialization), information seeking occurs repeatedly over the life cycle of one's career (Jablin, 2001; Rice, 1983; Svenning \& Ruchinskas, 1984). Organizations are dynamic and open systems that face a variety of procedural and structural changes as well as innovation challenges that frequently force members to adapt, cope, learn, assimilate, and reassimilate. For example, Lewis and Seibold's (1993, 1996) work underscores the prevalence of organizational innovations and indicates the critical role of communication in these innovations. Their work offers direction for this study by indicating that messages are critical to facilitating change at the organizational and individual levels. Moreover, Goodman 
and Griffith (1991) note that a primary challenge in contemporary, technology-intensive organizations is to "socialize multi-skilled individuals who work across boundaries, acquire knowledge across different roles, and are adaptive in their workplace communication habits" (p. 268, emphasis added).

Research indicates that there are opportunities for organizational member interactions and activities that can reduce individuals' uncertainty by providing information about normative organizational practices. These opportunities fall within what has been theoretically framed as organizational assimilation, the ongoing process by which persons learn the values, norms, and required behaviors that allow them to participate as members of organizations-and, acknowledging that it is a reciprocal process to which both organizational structures and members contribute, the experience during which members simultaneously define their roles and attempt to influence their organizations (Jablin, 2001; Myers \& Oetzel, 2003). Through this process members reduce anxiety associated with uncertainty they may have about their role in the organization.

\section{Contemporary Channels for Assimilation-related Information}

Nearly two decades ago, Steinfield (1984) and Jablin and Krone (1987) argued that organizational members' technology use serves a socializing function and requires new types of learning and socialization. Nevertheless, communication scholars have been slow to incorporate this claim into theories concerning organizational assimilation.

Historically, scholarly treatment of assimilation has been limited to the traditional communication channels that support uncertainty-reducing information, including formal and informal face-to-face interactions among organizational members and traditional paper documents such as memos, house newsletters, and training manuals (e.g., Allen \& Meyer, 1990; Fedor et al., 1997; Jablin, 2001; Lee et al., 1992; Meyer \& Allen, 1988; Miller, 1997; Miller \& Jablin, 1991). Organizational members' reliance on these traditional channels alone for uncertainty reduction is an unrealistic expectation in contemporary organizations. The use of ACITs for assimilationrelated communication may expand the number of opportunities available for actively seeking information that will contribute to successful organizational assimilation.

Consistent with Culnan and Markus's (1987) view of electronic media, ACITs are "interactive, computer-mediated technologies that facilitate two-way interpersonal communication among several individuals" by means of "written text, recorded or synthesized voice messages, graphical representation of communicators and/or data, or moving images of the communicators and/or message content" (p. 422). ACIT users are geographically dispersed and may use these technologies either synchronously or asynchronously. In addition, ACITs can be considered to "exist in a form that aids in communication ... to a significantly greater degree than did pre-1971 forms" (Huber, 1990, p. 238) because "the convergence of digital with 
analog technology has endowed the new media with significantly different capabilities" (Culnan \& Markus, 1987, p. 422). In light of the focus in this study on information processing over group decision making, decision support systems are excluded from ACITs. Whether organizational members heretofore have utilized more advanced communication technologies for uncertainty-reducing, assimilationrelated interaction, research attention has turned to these media for this purpose only recently.

ACITs common to organizations today include email, Internet and Web pages, Intranet, online chat facilities, voicemail, cellular telephones, online databases and calendars, communicating PDAs, instant messaging, videoconferencing, pagers, and fax. ${ }^{1}$ Although studies indicate that socializing information is difficult for organizational members to access (cf. Comer, 1991; Jablin, 1984; Teboul, 1994), the increased use of ACITs may expand opportunities to obtain information. Thus, as interactive and information-disseminating technologies proliferate, these technologies play an important role in members' assimilation by increasing the range of options available for acquiring information.

Technological advances have changed the availability of information, as well as the nature of communication and learning within contemporary organizations, in numerous ways. Although there are potential social costs associated with appearing unknowledgeable during information seeking (Callister, Kramer, \& Turban, 1999; Finkelstein, Kulas, \& Dages, 2003; Sias, Kramer, \& Jenkins, 1997), or being unfamiliar with the use of ACITs to do so, ACITs provide an important alternative to more traditional means for uncertainty reduction. Specifically, electronic communication and information technologies can carry more information, faster, at a lower cost, and to more people while also offering increased data communality, processing, and powerful recombinant capabilities (Beniger, 1996; Fulk \& DeSanctis, 1995). Second, advanced communication and information technologies extend the number and variety of people involved in organizational decisions (Huber, 1990; Sproull \& Kiesler, 1991). Third, others have noted that ACITs diminish temporal and physical interaction constraints (Eveland \& Bikson, 1988; Kaye \& Byrne, 1986) and increase horizontal and vertical communication (Hinds \& Kiesler, 1995).

Furthermore, Hiltz (1984) found that employees' use of electronic media increases the duration, frequency, and depth of their communication with colleagues both online and offline. Similarly, Johansen (1984) found that when electronic mail systems are implemented, the total amount of organizational communication increases-especially face-to-face communication. Thus, ACIT use appears to both supplement and encourage offline communication, and as a result, is likely to enhance assimilation-related communication efforts.

Researchers also have observed that ACITs such as email and teleconferencing make it possible for employees to form coalitions and acquire information (Jull, McCaughern, Mendenhall, Storey, Tassie, \& Zalatan, 1976; Sproull \& Kiesler, 1991). Others have found that ACITs may enhance workgroup performance. In an experiment comparing face-to-face (traditional) decision-making groups and those using computer-aided group decision support systems, Tan, Wei, and Raman (1993) 
found that groups using electronic support systems had higher consensus than groups not using the technology. Another study reveals the power of ACITs to increase exposure to and awareness of one's environment (Sproull \& Keisler, 1991). Organizational members' use of ACITs appears to provide an opportunity for them to build relationships and optimize the task-related benefits of those relationshipstwo key dimensions of effective assimilation to work groups and organizations (Anderson, Riddle, \& Martin, 2001; Lacoursiere, 1980; Moreland \& Levine, 1989; Tuckman, 1965).

Finally, Rice and Gattiker (2001) noted technology's profound capabilities to reprocess, combine, and analyze information in many forms from multiple sources. ACITs serve as a type of "discretionary database" (Connolly \& Thorn, 1990) that enables organizational members to access information critical to their effective assimilation. Connolly and Thorn noted that discretionary databases are "shared pools of data to which several participants ... may ... separately contribute information" (p. 221), and they are commonly supported by ACITs. Examples of assimilation-related information common to ACIT-enabled databases include expertise and experience of members, details of available workplace technologies, assessments of specific issues, contact with individuals, and evaluations of colleagues' abilities.

Thus, advanced communication and information technologies appear to increase the frequency and duration of organizational communication, promote cohesion and heightened group performance, and provide a forum for information exchange. A number of studies reveal that ACITs often facilitate increased levels of effective communication among work group and organizational members. Hence, ACITs simultaneously represent an additional and perhaps beneficial channel for obtaining assimilation-related information and for engaging in interactions key to assimilation.

Even in light of the documented ubiquity of ACITs in organizations and their theoretical importance for effective assimilation, their relative importance versus that of more traditional channels remains empirically undocumented. Consequently, the first research question probes user perceptions of mediated channels for assimilation-related uncertainty-reducing communication compared to more traditional channels-direct face-to-face communication and traditional media such as handbooks, newsletters, and other organizational documents.

RQ1:A What is the relationship between organizational members' selection and use of different types of information-seeking channels (i.e., ACITs, traditional technologies, and face-to-face communication) and their perceptions of assimilation effectiveness?

\section{Predictors of Selection and Use of ACITs}

Although a number of studies indicate that ACITs are pervasive in contemporary organizations, other research indicates that individual usage habits and attitudes toward ACITs vary across organizations and their members (Damanpour, 1991; Klein \& Sorra, 1996; Rice, 1993; Waldeck, Kearney, \& Plax, 2001; Yates \& Orlikowski, 1992). A particular ACIT's characteristics have important implications for 
individuals' reliance on that technology for assimilation-related communication and information seeking. The two most prominent theories of media selection and use include social presence and media richness.

\section{Social presence theory}

Short, Williams, and Christie (1976) conceptualized social presence as the degree to which a medium is perceived as conveying the presence of communicating participants. Social presence is a quality of communication media that is highly subjective- a perceptual or attitudinal dimension of the technology user. Social presence requirements for particular communication tasks (e.g., asking a procedural question, facilitating a personal relationship, collaborating on a research and development project) are based on "the degree of salience of the other person in the interaction and the consequent salience of the interpersonal relationship" (Short et al., p. 65). That is, persons assess the importance of interpersonal interaction in relationship to the complexity or ambiguity of a particular communication task and select a medium that facilitates the perceived requisite interpersonal contact. Short et al. reason that the greater the social presence afforded by a medium, the more likely people will be to use it for interpersonally involving tasks (such as complex or ambiguous ones). Accordingly, social presence theory posits that users will make an objective assessment of the social presence required by their task and select a medium for communicating that affords such interpersonalness.

A medium's capacity to transmit cues about an interactant's facial expression, posture, eye gaze, paralinguistic features, and verbal and nonverbal involvement in the encounter reflect its social presence. In addition, subtle aspects of interaction such as the apparent distance and the "realness" (Short et al., 1976, p. 74) of the other communicator(s) are important to users' perceptions of social presence. Short et al. note that socially present media promote intimacy (Argyle \& Dean, 1965) and immediacy (Mehrabian, 1971), and they have been demonstrated to contribute to users' perceptions of realistic communication, warmth, groupness, and vividness of communication. Rice (1993) observed that face-to-face communication was still rated most socially present by interactants, followed by telephone and meetings, desktop videoconferencing applications, voicemail, text, and electronic mail. Rice concluded that social presence theory "appears to provide a useful, consistent, meaningful, stable, and discriminating way to characterize media" (p. 457).

\section{Media richness theory}

Media richness theory also describes and predicts the use of communication media based on information processing requirements (e.g., uncertainty reduction) and media characteristics (Daft \& Lengel, 1984, 1986; Daft, Lengel, \& Trevino, 1987; Daft \& MacIntosh, 1981). Perceptions of media effectiveness are based on a match between information processing requirements and the channel selected. When people choose media that are sufficiently "rich" in relationship to the information task that they need to accomplish, they will perceive the use as effective. Trevino, 
Daft, and Lengel (1987) posit that "a mismatch may explain communication failures" (p. 573).

Richness refers to the ability of information and particular media to change human understanding, overcome differing conceptual frames of reference, or clarify ambiguity (Daft \& Lengel, 1984, 1986). Richness of a medium is based on four characteristics: speed of feedback, type of channels employed, personalness of the source, and richness of the language carried. Face-to-face communication is the richest medium for organizational communication, followed by telephone, email, written personal communications, written formal communications, and numeric data (Trevino et al., 1987; Trevino, Lengel, Bodensteiner, Gerloff, \& Muir, 1990b). Over time, information richness theory has been adapted to describe user decisions regarding more advanced media than those for which it was originally developed, including electronic mail, videoconferencing, and group decision support systems (Markus, 1994; Trevino et al., 1990). The theory also has been updated to reflect situational constraints and symbolic considerations as reasons for the use of particular media (Trevino et al., 1987). Trevino et al. (1990) conclude, "Media choice involves more than simple common sense. It is a complex process that is influenced by the interplay of messages, symbols, and contextual influences" (p. 92).

\section{ACIT characteristics and information seeking}

Assimilation-related information is complex and rich because it focuses on the critical yet highly implicit process of how persons fit into their environment, perform normatively-both socially and professionally-and learn about the nature of relationships within a particular organization. Thus, media that match the complexity of assimilation-related communication tasks are expected to be the most effective channels for uncertainty-reducing communication. Teboul (1994, p. 192) describes the assimilation experience as one in which "people ... do not know how to act, either because they have no familiar response to enact or because they derive multiple meanings and interpretations from their circumstances," emphasizing the challenging nature of the process and the need for interaction that can elicit complex information. Because organizational members report that their assimilation-related uncertainty-reduction efforts are challenging and complex (Morrison, 1993), ACITs that simulate rich and socially present interaction conditions will be effective for assimilation-related communication.

H1: Users' perceptions of the media richness and social presence of ACITs are positively related to organizational members' use of those ACITs for assimilation-related uncertainty reduction.

\section{User Responses to ACIT Use for Assimilation Purposes}

If ACITs perform an ongoing function in the assimilation efforts of organizational members, it is important to understand how users evaluate their experiences using 
ACITs and decide on continued use. One framework for investigating this issue is the social influence model of technology use (Fulk, Schmitz, \& Steinfield, 1990). This model flows from the work of Salancik and Pfeffer's (1978) social information processing theory, social learning theory (Bandura, 1977), and self-perception theory (Bem, 1972). Fulk et al. dealt with the effects of social influence on organizational members' perceptions of communication technology, arguing that persons influence each other's perceptions of a medium's appropriateness for a particular communication task.

Social influence proponents argue that organizational members will behave consistently with group and organizational norms for technology use (Fulk et al., 1990). Salient others in the organization influence both patterns of usage and perceptions of usage effectiveness by newcomers or others experiencing assimilation. Specifically, organizational members can influence other members' technology use and perceptions of technology effectiveness by: (a) providing feedback to others on their use of the medium, (b) using the medium themselves, and/or (c) explicitly communicating their own assessment of the medium.

A growing body of research supports social influence theory's application to ACIT use, and also serves as an important component in building an enhanced theory of organizational assimilation that reflects the effect of ACITs on uncertainty reduction. For instance, the use of technology by one's work group is positively related to individual technology use, especially when group attraction is high (Fulk, 1993; Orlikowski, Yates, Okamura, \& Fujimoto, 1995). Svenning and Ruchinskas (1984) found that the opinions of supervisors and co-workers were an important predictor of employee attitudes regarding videoconferencing technology. Managerial technology use also is an effective predictor of individual technology use (Markus, 1994). Schmitz and Fulk (1991) found that workers' perceptions of email usefulness varied with perceptions of colleagues and supervisors, and Fulk et al. (1990, p. 121) asserted that media usage patterns are the result of "attitudes, statements, and behavior of co-workers."

Additionally, organizational members' appropriate use of technology involves mastering their ingroup's usage norms (Markus, 1994; Sitkin, Sutcliffe, \& BarriosChoplin, 1992; Trevino et al., 1987). Markus suggested that a key dimension of technology use is to "behave appropriately," implying that using technology in a manner that is consistent with one's colleagues is crucial for effective assimilation. Thus, with regard to organizational assimilation and technology use, organizational members subtly and overtly send messages to their colleagues regarding what types of behaviors (e.g., information seeking and interaction) and sense making via mediated communication channels are acceptable in a work group or organization. Even stronger evidence for the influences of salient others during organizational assimilation comes from the classic works of Festinger (1954) and of Salancik and Pfeffer (1978), who indicated that persons rely on social comparison processes most frequently in ambiguous, equivocal situations marked by uncertainty. Numerous studies of organizations indicate that socialization/assimilation experiences are highly ambiguous and equivocal for members. 
There are numerous ways users may respond to their colleagues' feedback regarding their ACIT use. Based on positive feedback they might continue to use the ACIT in the same fashion. If they are critiqued or sanctioned for their ACIT use, they may discontinue or alter their ACIT-related practices. Thus, because social influence may be an important predictor of technology selection and use, and because social norms similarly impact evaluations of media use, it would be useful to determine whether there are specific responses to collegial feedback regarding ACIT use.

RQ2: How do organizational members respond to feedback regarding their ACIT use for assimilation-related uncertainty reduction?

\section{Method}

\section{Participating Organizations}

Members of four organizations in the western United States participated in this study. Each organization offered participants access to at least one ACIT. The four organizations each employed 200-700 employees. Larger organizations are more likely to share important structural characteristics with the population of organizations to which the results of this study might be generalized because they have larger spans of control and more complex coordination demands than small organizations (Lewis \& Seibold, 1996). In organizations of this size, frequent face-to-face communication among all members is difficult or impractical. In two of the four organizations studied, members do not work in the same physical building. As a result, it was thought that employees in these larger organizations ostensibly would take advantage of the ACITs to which they have access and thus be in a position to provide insightful responses.

Hotel $A^{2}$ is a mid-sized business-travel hotel located in the downtown business district of a large city on the west coast of the United States. Three departments participated in this project. The first, Administrative Offices, is comprised of the financial and sales staff. The second, Front Office, includes the hotel's front desk staff, the reservations staff, and the concierge, parking/valet, and bell staff. The third department, Food and Beverage, is formed by the catering, banquet, room service, and restaurant/bar staffs. Employees of these three Hotel A departments have access to networked computer applications, fax, teleconferencing, voicemail, cell phones and pagers, and a networked database called "Alpha," a standard application in the hospitality industry for tracking sales, planning, execution, and billing of hotel functions.

Hotel $B$ is a mid-sized luxury hotel in a resort destination on the United States west coast. Two departments were selected by the Human Resources Manager for inclusion. The first, Catering, is responsible for food and beverage service for banquet, meeting, and social functions. The second group, Lobby/Guest Services, is responsible for guest check-in and check-out, concierge, valet, switchboard, pool staff, and bell captain services. Employees in these two departments have access to 
networked computer applications, fax, teleconferencing, voicemail, cell phones and "Pages," a database similar to Alpha, and an Intranet.

Central Bank is located in a medium-sized city on the west coast and employs 650 employees in its corporate office and 27 branch offices. Departments represented included Customer Services, the staff of which is responsible for performing teller operations, such as accepting deposits and payments, recording transactions online, cashing checks, selling money orders, processing withdrawals, and marketing the bank's products and services. The second department, Banking Services, is responsible for opening new accounts and handling some loan and trust-related issues for customers. Each Banking Services staff member also maintains a portfolio of customers. Central Bank's Customer Services employees have access to email and Intranet. Banking Services has access to other ACITs: email and Intranet, Internet, and voicemail.

South County Association of Realtors (AOR) is the professional organization for real estate agents and brokers in a west coast county in the United States. AOR members rely heavily on email, cell phones, voicemail, Internet, and an online Multiple Listing Service (MLS), which allows agents to enter new property listings, search for property types by keywords, and make appointments to view properties listed by other agents.

\section{Participants}

Response rates. Across the four organizations 405 usable questionnaires were returned. Hotel A's response rate was 61\% $(n=107 / 175)$ with $30 \%$ (22 female, 10 male) from Administrative Offices, 31\% (19 male, 14 female) from Front Office, and $39 \%$ (13 male, 29 female) from Food and Beverage. Hotel B's response rate was $63 \%$ $(n=141 / 225)$, of which 40\% (26 male, 57 female) worked for Catering and 60\% (53 male, 31 female) for Lobby/Guest Services. The overall response rate from Central Bank was $61 \%(n=87 / 143)$ with $69 \%$ from Customer Services (22 female, 38 female) and $31 \%$ from Banking Services. Finally, the response rate for AOR was $58 \%$ ( $n=70 / 120 ; 23$ male, 47 female).

Demographic characteristics by organization. At Hotel A the mean age of respondents was 33 years (range 22-53), mean length of employment 3.2 years (range 3 months -7 years), and the majority of respondents (54\%) were Caucasian/White; 37\% were Latino/a, 3\% African American, and 6\% other. The mean age at Hotel B was 28 (range 18-61), average length of employment 6.25 years (range 2 months-17 years), and 47\% were Caucasian/White, 43\% Latino/a, 4\% Asian American, and 6\% other. The mean age of participants at Central Bank was 38 (range 20-65), and average length of employment was 6 years (6 months-27 years). Of these, $76 \%$ identified themselves as Caucasian/White, 8\% Latino/a, 3\% African American, and $13 \%$ other. At AOR, the mean age was 42 (32-66), with the mean length of career 14 years. Regarding ethnicity, 90\% identified themselves as Caucasian/White.

ACIT use. Because the issue under investigation was related to participants' familiarity with and access to ACITs, participants were asked a number of questions regarding their access to, experience with, and attitudes toward computer-aided 
communication technologies. In response, $1 \%$ indicated that they had been using a computer to communicate with others for 7 years or more, $70 \%$ for $4-6$ years, $17 \%$ for $1-3$ years, and $12 \%$ for less than 1 year. ${ }^{3}$ Respondents were asked how often they used ACITs for work-related purposes, and 84\% indicated that used ACITs every day, $11 \%$ reported that used ACITs on an hourly basis, $3 \%$ on a weekly basis, and $2 \%$ indicated that they never used ACITs for work-related purposes.

\section{Procedures}

The questionnaire was derived from interviews conducted with members of each organization, and it was extensively pilot tested prior to administration. Based in part on these interviews, scenarios that represented prototypical, natural, and recognizable organizational assimilation experiences were developed. To capture the range of assimilation experiences, these scenarios depicted each type of organizational assimilation-related uncertainty (referent, appraisal, and technical information). Written scenarios developed in this manner were used as stimuli for participant responses. Each scenario was followed by a space for participants to describe a situation in which they experienced uncertainty similar to that described in the scenario. Respondents then completed the measures described in the following section while recalling the situations about which they were asked to write.

\section{Measures}

Assimilation effectiveness was assessed by three measures that have been used in exemplar studies of socialization-related information seeking as dimensions of organizational assimilation effectiveness (e.g., Ashford, 1986; Jones, 1986; Miller, 1997; Miller \& Jablin, 1991; Morrison, 1993, 2002). Each of these three measures employed a 5-point Likert-type scale (ranging from $5=$ strongly agree to $1=$ strongly disagree). Role clarity was assessed using four items developed by Ashford (1986) that measure the extent to which persons understand the various behavioral requirements in an organizational setting of their roles and can predict outcomes of their behaviors (Cronbach's alpha $=.91$ ). Performance/task mastery was assessed with Morrison's (1993) four-item self-appraisal scale, which measures confidence in the quality of work, amount of effort exerted, and ability to work effectively with colleagues (Cronbach's alpha $=.79$ ). Although self-evaluations of performance may be prone to social desirability effects, Harris and Schaubroeck (1988) concluded in a meta-analytic review that self-ratings of performance during the socialization period are moderately to highly correlated with both supervisor and peer ratings. Finally, social integration was measured with a four-item scale reported by Morrison (1993) (Cronbach's alpha $=.86$ ).

To test for discriminant validity the items from the role clarity, task mastery, and social integration scales were factor analyzed together with a varimax rotation. The results indicated that the items corresponding to the three different scales loaded on three separate factors. The criteria for interpreting the analysis were as follows: (a) an item was considered loaded on a factor when it posted a primary loading of at least .50 with no secondary loading higher than .30 , and (b) an eigenvalue of 1.00 
was set to terminate factor extraction. Factor 1 corresponded with the role clarity items $(M=3.89, S D=0.46)$, factor 2 corresponded with the social integration items $(M=4.00, S D=0.44)$, and factor 3 corresponded with the task mastery items $(M=3.99, S D=1.11)^{4}$

Communication channel selection and use. While considering the written scenarios, participants were asked to recall the degree to which they "were able to get useful information" (ranging from $5=$ to a great extent to $1=$ not at all) to reduce their assimilation-related uncertainty using each of 12 communication channels. Channels were selected to represent three categories of communication media: ACITs (email, voicemail, Intranets, cell phones, teleconferencing, videoconferencing, online/electronic scheduling programs, online chat, and portions of the Web accessible to the public), traditional technologies (one-to-one telephone conversations, excluding those over cellular phones, and hardcopy materials including handbooks, memos, newsletters, and other written materials), and face-to-face communication channels. Traditional channels were selected largely based on their inclusion in the ICA Audit (Goldhaber \& Rogers, 1978) and ACITs were derived from preliminary interview responses indicating current, widespread organizational technology usage. A mean channel selection/use score was calculated for each participant, based on reported usage of the media in each category, summed across all three uncertainty situations depicted in the written scenario. Thus, each respondent had three mean channel selection/use scores: one for ACIT use, one for traditional technology use, and one for face-to-face communication.

Perceptions of ACIT richness/social presence. Rice's (1993) media appropriateness scale was used to measure the perceived media richness/social presence of ACITs. Rice found that communication tasks requiring a high degree of richness/social presence include: exchanging confidential information, negotiating/bargaining, getting to know someone, generating ideas, resolving disagreements, and making decisions. Those requiring low richness/presence include: exchanging information, staying in touch, asking questions, and exchanging time-sensitive information.

After reading the written assimilation scenarios, participants were prompted to describe a personal scenario in which they used an ACIT for uncertainty reduction. Participants were then instructed to think of the one ACIT (from the list provided) they used in that situation and, if they used more than one, to consider the technology "they relied on most frequently" in that situation. With this ACIT in mind, participants were asked about the appropriateness of using that technology for each of the tasks in the media appropriateness scale. Responses on these items were captured on a 5 -point scale (where $1=$ inappropriate to $5=$ appropriate) and were submitted to principal components analysis, which indicated that these items loaded on two factors. Consistent with Rice's (1993) findings, factor 1 was comprised of the items theorized to measure high social presence and factor 2 was comprised of the items theorized to measure low social presence. Responses within each dimension (high and low richness/presence) were summed to determine participants' perceptions of the richness/social presence of ACITs, as indicated by the channel they indicated using for assimilation-related uncertainty reduction. 
Responses to ACIT-related feedback. Consistent with procedures employed by Contractor, Seibold, and Heller (1996) and Rice and Aydin (1991), participants were asked to describe what they said or did in response to feedback they received from colleagues regarding their selection and use of technology. Specifically, participants were prompted to indicate how they responded to feedback from others with regard to their ACIT use for reducing assimilation-related uncertainty. For example, participants were prompted, "For instance, maybe you tried to use the technology again, but differently from your first attempt, in response to feedback from colleagues."

Participant responses were then unitized, coded, defined, and labeled. In stage 1 of this process, two trained coders read a sample of the raw units in order to become familiar with the data. They subsequently unitized the data into separate and discrete categories of responses. In stage 2 the same two coders independently read each discrete unit and placed them into categories containing conceptually or operationally similar words and phrases. In stage 3 both of the coders reread all of the responses in each category to check for internal consistency, assigned tentative labels to each class of units, and defined preliminary category descriptions. In stage 4 the coders reread the responses and, based on the labels and definitions, made necessary revisions to each category.

Stage 5 involved two additional coders also trained in content-analytic procedures, who recategorized units randomly selected from each category (15\% from each category). Percentage of unit-by-unit intercoder agreement between the original coders and the additional two coders ranged from $88 \%$ to $100 \%$ depending on the category. Intercoder agreement among all coders, assessed by unit-by-unit agreement (Landis \& Loch, 1977), was .91. Five categories were derived in this manner: Continue Current Practices, Supplement Channel, Discontinue Use, Expand Use, and Learn New Uses.

\section{Results}

\section{Tests for Organizational Differences}

Prior to tests of the hypothesis and research questions the data were examined for differences among organizations on the variables of interest. A GLM Multivariate analysis was used to compare the four organizations on use of assimilation-related uncertainty reduction channels, assimilation effectiveness, and user perceptions of ACIT social presence.

According to the Wilks' criterion the combined variables were not statistically significantly affected by organization, $F(3,379)=1.064$, n.s. That is, no statistically significant differences were found among organizations on the primary variables of interest. Thus, the results of this initial analysis indicated that examining the four organizations as a single sample is reasonable. 


\section{Relationship Between Channel Selection/Use and Assimilation Effectiveness}

Research question 1 addressed the relationship between organizational members' selection and use of different types of information-seeking channels and their perceptions of assimilation effectiveness. To assess this relationship an OLS multiple regression analysis was performed with channel selection/use scores for each of the three channel types (ACITs, traditional technologies, and face-to-face communication), along with several demographic variables (user age, reported length of use of computers for communicating with others, and length of employment in the organization) as the independent variables, and perceived assimilation effectiveness as the criterion measure. With all variables in the equation, $F(6,399)=182.18$, $p<.01$, adjusted $R^{2}=.57$, face-to-face communication $(\beta=.281 ; p<.01)$, ACITs $(\beta=.263, p<.05)$, and traditional technology $(\beta=.144, p<.05)$ were all significant predictors of assimilation effectiveness. Participant demographic factors were not statistically significant predictors in this model.

\section{User Perceptions of ACIT Richness/Presence and ACIT Use}

Hypothesis 1 proposed that user perceptions of ACIT richness/social presence are positively related to organizational members' use of ACITs for the reduction of assimilation-related uncertainties. Rice (1993) indicated that high social presence activities include exchanging confidential information, negotiating/bargaining, getting to know someone, generating ideas, resolving disagreements, and making decisions. Thus, the sum of these items was entered into an OLS multiple regression analysis, along with participant age (Finkelstein et al., 2003), reported length of use of ACITs, and length of present employment. Frequency with which persons reported using that particular ACIT was the single criterion. With all variables in the equation, $F(4,401)=252.03, p<.05$, adjusted $R^{2}=.29$, only perceptions of media richness/social presence $(\beta=.164, p<.05)$ contributed significantly to the equation, in support of hypothesis 1 .

\section{Responses to ACIT-related Feedback}

Research question 2 asked how participants respond to feedback they receive regarding their ACIT use for assimilation-related uncertainty reduction. Of the five response strategies (Continue Current Practices, Supplement Channel, Discontinue Use, Expand Use, and Learn New Uses), the first and most frequently cited category that emerged was Supplement Channel $(n=191 ; 49 \%)$. Organizational members who reported a response in this category found that they needed to supplement the information they acquired through ACIT use with information from some other ACIT, a more traditional technology (such as a handbook), or face-to-face communication. For instance, a respondent from Central Bank reported, "I still didn't quite understand what the policy regarding sick leave was, so I had to ask my supervisor." 
The next most frequently cited category was Expand Use $(n=111 ; 29 \%)$. Responses in this category indicated that persons used the ACIT more frequently, to communicate with additional people, or for additional information-seeking tasks. For example, one respondent from Hotel B wrote, "I learned how quick and convenient it was! I began to e-mail everyone. My phone use was cut way back. I learned that most of what I need to say to others at work can be said over e-mail."

Category 3, Continue Current Practices $(n=37 ; 10 \%)$, reflected responses from participants who simply continued to use the ACIT for the same or similar purposes, in the same way, or with the same frequency, based on feedback from others. For example, an employee from Hotel B wrote, "I just kept using the technology. It worked, it was easy to use, and I had no problems with it. I wouldn't do anything differently." The fourth category was Learn New Uses $(n=27 ; 8 \%)$. Those who reported enacting responses from this category discovered new uses for an ACIT by accident and began to use the technology for information seeking or uncertainty reduction. For instance, one person from Hotel A wrote, "I was looking for a telephone number on our Intranet and found a whole section with answers to frequently asked questions that precluded me from needing to phone the person for an answer, so I continued to go back to that section for a long time until I became more knowledgeable/experienced."

Category 5, and the least most frequently used response-Discontinue Use $(n=22 ; 6 \%)$-included responses from persons who stopped using the technology in response to their assimilation-related ACIT experience. For example, one person from Hotel B indicated, "My attempt to use e-mail for this reason was completely ineffective. It made me down on the whole use of e-mail. I don't use it anymore, especially for talking about issues related to my performance reviews." Another simply wrote, "I stopped using this technology altogether." Analyses to determine whether participant demographic characteristics influenced the responses indicated no relationships.

\section{Discussion}

This study represents the first investigation of the use of advanced communication and information technologies for reducing three types of uncertainties (referent, appraisal, and technical) common to persons experiencing organizational assimilation. Furthermore, and unlike past studies that focused primarily on the assimilation experiences of organizational newcomers, assimilation was conceptualized broadly to include the numerous changes, transitions, and innovations with which all members of contemporary organizations must cope. Finally, this study also represented the first empirical investigation of an important function of organizational ACITs - assisting organizations and their members in learning often-changing organizational technical, evaluative, and relational norms.

The results indicate that ACIT use is related to organizational members' perceptions of the effectiveness of their assimilation. Face-to-face communication appears to be the most important predictor of effective assimilation, and traditional 
technologies (such as handbooks, memos, other written materials, and telephone conversations) are the least predictive of assimilation effectiveness. Thus, ACITs fall between face-to-face communication and traditional technologies as sources of assimilation-related information and uncertainty-reducing interaction.

These results are encouraging in terms of the usefulness of advanced communication and information technologies for assimilation-related purposes. Although face-to-face interpersonal interaction is closely related to and highly predictive of effective organizational assimilation, contemporary media also appear to be quite important to efforts to assimilate. This finding provides additional empirical support for the attention that new media have received in organizational circles as being convenient, useful, and important tools for communicating and seeking information. Moreover, given the massive costs of many technologies-both in terms of financial costs and the time required to master their use-it is encouraging to discover that they are valuable for such a critical organizational practice.

For instance, in focus group interviews with members of all four organizations conducted after the survey data were collected, employees indicated that they learn a great deal about their colleagues through email exchanges. One individual said:

I periodically tried to initiate social get-togethers with a colleague and she repeatedly turned me down. Over the course of several e-mails with a co-worker, I learned that she had a child with a disability who required a lot of care. She didn't get out much except to go to work. She disclosed details bit-by-bit, and I gained new understanding of why she related to me the way she did.

Another organizational member noted that "I use our company's Intranet to find rules, policies, and information about my job description. There is a lot of littleknown information there that I have found really helpful." And another person offered an example of how she used ACITs to acquire information related to how she will be appraised by her supervisor:

My supervisor posts daily "to-dos" on our [online] calendar system. They are often little extras that I might not normally think to do in the course of a day, but seeing the reminder prompts me to do them and lets me know what is important to her right then, on that day.

The fact that traditional technology (e.g., company handbooks, memos, newsletters, and traditional telephone conversations) is the least important predictor may indicate the growing acceptance of and reliance on more advanced technologies in the workplace. Networked computers, digital procurement tools that allow employees to order their supplies online, and Intranets that meet organizational members' administrative/human resource needs (such as access to benefit information, personnel records, and the like) are making the paperless office more of a reality. For example, Central Bank's employee handbook no longer exists in paper form. Although some employees with longer tenure reported in interviews that they still rely on old hard copy versions of their handbook, they acknowledged that the most up-to-date information could only be found online. 
These findings are interesting in terms of advancing assimilation theory as well. Communication researchers have so emphasized the importance and necessity of face-to-face human interaction (Anderson \& Nussbaum, 1990) that they may have de-emphasized the role of advanced technologies as communication channels. Even though ACITs are not new to organizations (for assimilation-related communication in particular), the research attention focusing on their use has only recently been separated from attention to communication in general. The findings reported here indicate that a theory of organizational assimilation, and organizational communication more broadly, must include some treatment of ACITs as vehicles for attaining socialization goals. Future theoretical models would profit by including explanations of why people select ACITs for some assimilation-related activities and not for others, and to what ends their selections lead them (cf. Orlikowski, 1992).

\section{User Perceptions of ACIT Attributes and ACIT Use}

Hypothesis 1 proposed that organizational members' perceptions of media richness and social presence are positively related to their ACIT use. Analyses revealed that perceptions of media attributes are predictive of ACIT use, and that continued use of ACITs also has an impact on perceptions of their appropriateness for various communication tasks.

Overall, participants in this study reported using ACITs that they perceived to be appropriate for communication tasks requiring a high degree of social presence. Rice (1993) indicated that six tasks-exchanging confidential information, negotiating/ bargaining, getting to know someone, generating ideas, resolving disagreements, and making decisions - require a socially present medium, and that the remaining tasks measured by his scale_-asking questions, staying in touch, exchanging time-sensitive information, and exchanging information-required less social presence. In this investigation a comparison of means on these two subsets of Rice's measure indicated that respondents selected ACITs for reducing assimilation-related uncertainty most frequently that were high in social presence/richness. Thus, organizational members' perceptions of the social presence of the medium they reported using most frequently are positively related to their overall use of ACITs for assimilation-related uncertainty reduction. A longitudinal study is necessary to determine the ongoing cyclical relationship between perceptions of ACIT attributes and use. Furthermore, work in this area might include a study that employs the appropriate measure of the richness of face-to-face and traditionally mediated communication so that the three can be compared. In this study, however, only the richness of ACITs was assessed.

In addition, although this study demonstrated the importance of ACITs in assimilation-related information seeking relative to other channels, future work could focus more on the ways in which users supplement the information they receive via ACITs with communication over other channels. The current results indicate that organizational members employ channels in addition to ACITs. Future work might investigate the ways in which organizational members assess and 
scrutinize the information they acquire via ACITs and focus on how, why, and to what end they select additional channels to supplement the information.

The second research question asked how persons respond to feedback they receive regarding their ACIT use. Five diverse responses were derived inductively: Continue Current Practices, Supplement Channel, Discontinue Use, Expand Use, and Learn New Uses. Results indicated that organizational members' initial experiences trying out ACITs for uncertainty reduction are highly influential, and that feedback related to their ACIT selection and use are important determinants of how they subsequently use and respond to the ACIT. Initial failures to obtain necessary information in a timely fashion, for example, may prompt members to discontinue their use of an ACIT for similar purposes, as in the case of one respondent who wrote, "I found the whole effort a big waste of time because it didn't end up working for me. I won't even try to use it again."

Discontinuing Usage was the least frequently reported response to technology use for assimilation-related information gathering. Instead, feedback and perceived outcomes of technology use were most likely to lead employees to supplement the information they acquired through ACITs with other communication channels, use the ACIT more frequently and perhaps to communicate with more people, continue using the ACIT consistently with their initial attempt, or learn new uses for the ACIT beyond their initial one(s). Thus, the range of organizational members' responses to feedback regarding their ACIT use is broad, and the typology derived in this study further illustrates that assimilation-related uses of ACITs begin the process of sensitizing users to environmental norms for media selection and use.

These categories represent a rich compilation of data on both assimilation practices and innovation uses and modification. A future report could address the relationship between features of the media persons reported using (e.g., social presence/richness) and the particular response categories indicated. In this way, a better understanding would accrue of whether specific coping responses and innovation modifications (Lewis \& Seibold, 1996) are associated with media possessing particular characteristics.

This study represents an advance in organizational assimilation theory by broadly defining the types of experiences that constitute assimilation. This advance reflects the frequent changes and innovations with which organizational members must cope, and the widespread trend toward the "learning organization" (Senge, 1990). More than ever, on this view, organizations are dynamic structures that require learning and change at both the individual and organizational levels. Thus, basic principles from the organizational assimilation literature might be revisited to determine if their characterization changes when assimilation is conceptualized as an ongoing process. Because rapidity of organizational socialization has become an increasing focus in the literature (Cooper-Thomas \& Anderson, 2002), the speed inherent in organizational technology innovation cycles, in users' appropriation of those innovations, and in their utility for assimilation may all contribute to research on the speed with which organizational assimilation occurs. 


\section{Notes}

[1] Given the rapid rate of technological change, it is always risky to label technologies as "advanced." Nonetheless, this definition of ACITs serves to highlight important characteristics of contemporary media that functionally distinguish them from more "traditional" media, a term that is also in historical flux.

[2] The identities of the organizations and their members have been disguised to assure anonymity. The changes maintain the descriptive spirit of the organizations and their characteristics so that the reader may gain insight into the characteristics of participating organizations.

[3] Data were collected in 1999.

[4] Factor analysis results and a full correlation matrix are available from the first author.

\section{References}

Allen, N. J., \& Meyer, J. P. (1990). Organizational socialization tactics: A longitudinal analysis of links to newcomers' commitment and role orientation. Academy of Management Journal, 33, $847-858$.

Andersen, J., \& Nussbaum, J. F. (1990). Interaction skill in instructional settings. In J. Daly, G. Friedrich, \& A. Vangelisti (Eds.), Teaching communication: Theory, research, and methods (pp. 301-316). Hillsdale, NJ: Lawrence Erlbaum Associates, Inc.

Anderson, C. M., Riddle, B. L., \& Martin, M. M. (2001). Socialization processes in groups. In L. R. Frey (Ed.), Handbook of small group communication (pp. 139-163). Newbury Park, CA: Sage.

Argyle, M., \& Dean, B. F. (1965). The social psychology of intimacy. In M. Argyle (Ed.), The social psychology of interpersonal behaviour. Harmondsworth, UK: Penguin.

Ashford, S. J. (1986). The role of feedback seeking in individual adaptation: A resource perspective. Academy of Management Journal, 29, 465-487.

Bandura, A. (1977). Social learning theory. Englewood Cliffs, NJ: Prentice-Hall.

Bem, D. J. (1972). Self perception theory. In L. Berkowtiz (Ed.), Advances in experimental psychology (Vol. 6, pp. 1-62). New York: Academic Press.

Beniger, J. R. (1996). Who shall control cyberspace? In L. Strate, R. Jacobson, \& S. B. Gibson (Eds.), Communication and cyberspace: Social interaction in an electronic environment (pp. 49-58). Cresskill, NJ: Hampton Press.

Callister, R. R., Kramer, M. W., \& Turban, D. B. (1999). Feedback seeking following career transitions. Academy of Management Journal, 42, 429-438.

Comer, D. R. (1991). Organizational newcomers' acquisition of information from peers. Management Communication Quarterly, 5, 64-89.

Connolly, T., \& Thorn, B. K. (1990). Discretionary databases: Theory, data, and implications. In J. Fulk \& C. Steinfield (Eds.), Organizations and communication technology. Thousand Oaks, CA: Sage.

Contractor, N. S., Seibold, D. R., \& Heller, M. A. (1996). Interactional influence in the structuring of media use in groups: Influence in members' perceptions of group decision support system use. Human Communication Research, 22, 451-481.

Cooper-Thomas, H., \& Anderson, N. (2002). Newcomer-adjustment: The relationship between organizational socialization tactics, information acquisition and attitudes. Journal of Occupational and Organizational Psychology, 75, 423-437.

Culnan, M. J., \& Markus, M. L. (1987). Information technologies. In F. M. Jablin, K. H. Roberts, L. L. Putnam, \& L. W. Porter (Eds.), Handbook of organizational communication: An interdisciplinary perspective (pp. 420-443). Newbury Park, CA: Sage.

Daft, R. L., \& Lengel, R. H. (1984). Information richness: A new approach to managerial behavior and organization design. Research in Organizational Behavior, 6, 191-233.

Daft, R. L., \& Lengel, R. H. (1986). Organizational information requirements, media richness, and structural design. Management Science, 32, 554-571. 
Daft, R. L., Lengel, R. H., \& Trevino, L. K. (1987). Message equivocality, media selection, and manager performance: Implications for information systems. MIS Quarterly, September, 355-366.

Daft, R. L., \& MacIntosh, N. B. (1981). A tentative exploration into the among and equivocality of information processing in organizational work units. Administrative Science Quarterly, 26, 207-224.

Damanpour, F. (1991). Organizational innovation: A meta-analysis of effects of determinants and moderators. Academy of Management Journal, 34, 555-590.

Eveland, J. D., \& Bikson, T. K. (1988). Work group structures and computer support: A field experiment. Transactions on Office Information Systems, 6, 354-379.

Fedor, D. B., Buckley, M. R., \& Davis, W. D. (1997). A model of the effects of realistic job previews. International Journal of Management, 14, 211-221.

Feldman, D. C. (1976). A contingency theory of socialization. Administrative Science Quarterly, 21, 433-452.

Festinger, L. (1954). A theory of social comparison processes. Human Relations, 7, 117-140.

Finkelstein, L. M., Kulas, J. T., \& Dages, K. D. (2003). Age differences in proactive newcomer socialization strategies in two populations. Journal of Business and Psychology, 17, 473-502.

Fulk, J. (1993). Social construction of communication technology. Academy of Management Journal, 36, 921-950.

Fulk, J., \& DeSanctis, G. (1995). Electronic communication and changing organizational forms. Organization Science, 6, 337-349.

Fulk, J., Schmitz, J., \& Steinfield, C. W. (1990). A social influence model of technology use. In J. Fulk \& C. W. Steinfield (Eds.), Organizations and communication technology (pp. 117-140). Thousand Oaks, CA: Sage.

Goldhaber, G. M., \& Rogers, O. P. (1978). Auditing organizational communication systems: The ICA communication audit. Buffalo, NY: State University of New York.

Goodman, P. S., \& Griffith, T. L. (1991). A process approach to the implementation of new technology. Journal of Engineering and Technology Management, 8, 261-285.

Harris, M. M., \& Schaubroeck, M. (1988). A meta-analysis of self-supervisor, self-peer, and peer-supervisor ratings. Personnel Psychology, 41, 43-61.

Hart, Z., Miller, V., \& Johnson, J. (1998, November). The socialization of new hires and resocialization of incumbents: The role of tactics and communication relationships. Paper presented at the annual meeting of the National Communication Association, New York.

Hiltz, S. R. (1984). Online communities: A case study of the office of the future. Norwood, NJ: Ablex.

Hinds, P., \& Kiesler, S. (1995). Communication across boundaries: Work, structure, and use of communication technologies in a large organization. Organization Science, 6, 373-393.

Huber, G. P. (1990). A theory of the effects of advanced information technologies on organizational design, intelligence, and decision making. In J. Fulk \& C. W. Steinfield (Eds.), Organizations and communication technology (pp. 237-274). Newbury Park, CA: Sage.

Jablin, F. M. (1982). Organizational communication: An assimilation approach. In M. E. Roloff \& C. R. Berger (Eds.), Social cognition and communication (pp. 255-286). Beverly Hills, CA: Sage.

Jablin, F. M. (1984). Assimilating new members into organizations. In R. Bostrom (Ed.), Communication yearbook (Vol. 8. pp. 594-626). Beverly Hills, CA: Sage.

Jablin, F. M. (1987). Organizational entry, assimilation, and exit. In F. M. Jablin, L. L. Putnam, K. H. Roberts, \& L. W. Porter (Eds.), Handbook of organizational communication (pp. 679740). Newbury Park, CA: Sage.

Jablin, F. M. (2001). Organizational entry, assimilation, and disengagement/entry. In F. M. Jablin \& L. L. Putnam (Eds.), The new handbook of organizational communication: Advances in theory, research, and methods (pp. 732-818). Thousand Oaks, CA: Sage.

Jablin, F. M., \& Krone, K. J. (1987). Organizational assimilation. In C. R. Berger \& S. H. Chaffee (Eds.), Handbook of communication science (pp. 711-746). Newbury Park, CA: Sage.

Johansen, R. (1984). Teleconferencing and beyond. New York: McGraw-Hill. 
Jones, G. R. (1986). Socialization tactics, self-efficacy, and newcomers' adjustments to organizations. Academy of Management Journal, 29, 262-279.

Jull, W., McCaughern, R. W., Mendenhall, N. M., Storey, J. R., Tassie, A. W., \& Zalatan, A. (1976). Research report on teleconferencing. Ottawa, Canada: Communications Research Center.

Kaye, A. R., \& Byrne, K. E. (1986). Insights on the implementation of a computer-based message system. Information and Management, 10, 277-284.

Klein, K. J., \& Sorra, J. S. (1996). The challenge of innovation implementation. Academy of Management Review, 21, 1055-1080.

Kramer, M. W. (1989). Communication during introrganizational job transfers: Leaving and joining processes. Management Communication Quarterly, 3, 219-248.

Kramer, M. W. (1993). Communication and uncertainty reduction during job transfers: Leaving and joining processes. Communication Monographs, 60, 178-198.

Kramer, M. W., Callister, R. R., \& Turban, D. T. (1995). Information-receiving and informationgiving during job transitions. Western Journal of Communication, 59, 151-180.

Kramer, M. W., \& Noland, T. L. (1999). Communication during job promotions: A case of ongoing assimilation. Journal of Applied Communication Research, 27, 335-355.

Lacoursiere, R. B. (1980). The life cycle of groups: Group developmental stage theory. New York: Human Sciences Press.

Landis, J. R., \& Loch, G. G. (1977). The measurement of observer agreement for categorical data. Biometrics, 33, 159-174.

Lee, T. W., Ashford, S. J., Walsh, J. P., \& Mowday, R. T. (1992). Commitment propensity, organizational commitment, and voluntary turnover: A longitudinal study of organizational entry processes. Journal of Management, 18, 15-34.

Lewis, L. K., \& Seibold, D. R. (1993). Innovation modification during intraorganizational adoption. Academy of Management Review, 18, 322-354.

Lewis, L. K., \& Seibold, D. R. (1996). Communication during intraorganizational adoption: Predicting users' behavioral coping responses to innovations in organizations. Communication Monographs, 63, 131-157.

Markus, M. L. (1994). Electronic mail as the medium of managerial choice. Organization Science, 5, 502-527.

Mehrabian, A. (1971). Silent messages. Belmont, CA: Wadsworth.

Meyer, J. P., \& Allen, N. J. (1988). Links between work experiences and organizational commitment during the first years of employment: A longitudinal analysis. Journal of Occupational Psychology, 61, 195-209.

Miller, V. D. (1997). An experimental study of newcomers' information seeking behaviors during organizational entry. Communication Studies, 48, 1-24.

Miller, V. D., \& Jablin, F. M. (1991). Information seeking during organizational entry: Influences, tactics, and a model of the process. Academy of Management Review, 16, 92-120.

Moreland, R. L., \& Levine, J. M. (1989). Newcomers and oldtimers in small groups. In P. B. Paulus (Ed.), Psychology of group influence (2nd ed., pp. 144-186). Hillsdale, NJ: Lawrence Erlbaum Associates, Inc.

Morrison, E. W. (1993). Newcomer information seeking: Exploring types, modes, sources, and outcomes. Academy of Management Journal, 36, 557-589.

Morrison, E. W. (2002). Newcomers' relationships: The role of social network ties during socialization. Academy of Management Journal, 45, 1149-1160.

Myers, K. K., \& Oetzel, J. G. (2003). Exploring the dimensions of organizational assimilation. Communication Quarterly, 51, 438-457.

Orlikowski, W. J. (1992). The duality of technology: Rethinking the concept of technology in organizations. Organizational Science, 3, 398-427.

Orlikowski, W. J., Yates, J., Okamura, K., \& Fujimoto, M. (1995). Shaping electronic communication: The metastructuring of technology in the context of use. Organization Science, 6, 423-444.

Rice, R. E. (1983). Mediated group communication. In R. E. Rice \& Associates (Eds.), The new media: Communication, research, and technology (pp. 129-154). Beverly Hills, CA: Sage.

Rice, R. E. (1993). Media appropriateness: Using social presence theory to compare traditional and new organizational media. Human Communication Research, 19, 451-484. 
Rice, R. E., \& Aydin, C. (1991). Attitudes toward new organizational technology: Network proximity as a mechanism for social information processing. Administrative Science Quarterly, 36, 219-244.

Rice, R. E., \& Gattiker, U. E. (2001). New media and organizational structuring. In F. M. Jablin \& L. L. Putnam (Eds.), The new handbook of organizational communication: Advances in theory, research, and methods (pp. 544-581). Thousand Oaks, CA: Sage.

Salancik, G. R., \& Pfeffer, J. (1978). A social information processing approach to job attitudes and task design. Administrative Science Quarterly, 23, 224-253.

Schmitz, J., \& Fulk, J. (1991). Organizational colleagues, media richness, and electronic mail: A test of the social influence model of technology use. Communication Research, 18, 487-523.

Senge, P. M. (1990). The fifth discipline: The art and practice of the learning organization. New York: Doubleday.

Short, J., Williams, E., \& Christie, B. (1976). The social psychology of telecommunications (pp. 6176). London: Wiley.

Sias, P. M., Kramer, M. W., \& Jenkins, E. (1997). A comparison of communication behaviors of temporary employees and new hires. Communication Research, 24, 731-754.

Sitkin, S. B., Sutcliffe, K. M., \& Barrios-Choplin, J. R. (1992). A dual-capacity model of communication media choice in organizations. Human Communication Research, 18, $563-598$.

Sproull, L., \& Kiesler, S. (1991). Connections: New ways of working in the networked organization. Cambridge, MA: MIT Press.

Steinfield, C. (1984, May). The nature of electronic mail usage in organizations: Purposes and dimensions of use. Paper presented to the annual meeting of the International Communication Association, San Francisco.

Steinfield, C. W., \& Fulk, J. (1989, August). New information technology and communication media: An information processing view. Paper presented at the Academy of Management, Chicago.

Svenning, L., \& Ruchinskas, J. (1984). Organizational teleconferencing. In R. Rice \& Associates (Eds.), The new media: Communication, research, and technology (pp. 217-248). Beverly Hills, CA: Sage.

Tan, B. C. Y., Wei, K. K., \& Raman, K. S. (1993). Impact of task-medium fit on effectiveness and efficiency in GDSS supported meetings. Local area network applications: Leveraging the LAN (pp. 161-175). Amsterdam: IFIP Transactions A-31.

Teboul, J. C. B. (1994). Facing and coping with uncertainty during organizational encounter. Management Communication Quarterly, 8, 190-224.

Trevino, L. K., Daft, R. L., \& Lengel, R. H. (1987). Understanding managers' media choices: A symbolic interactionist perspective. In R. Rice \& Associates (Eds.), The new media: Communication, research, and technology (pp. 71-94). Beverly Hills, CA: Sage.

Trevino, L. K., Lengel, R. H., Bodensteiner, W., Gerloff, E. A., \& Muir, N. K. (1990). The richness imperative and cognitive style: The role of individual differences in media choice behavior. Management Communication Quarterly, 4(2), 176-197.

Trevino, L. K., Lengel, R. H., \& Daft, R. L. (1987). Media symbolism, media richness, and media choice in organizations: A symbolic interactionist perspective. Communication Research, 14, 553-575.

Tuckman, B. W. (1965). Developmental sequence in small groups. Psychological Bulletin, 63, 384-399.

Waldeck, J. H., Kearney, P., \& Plax, T. G. (2001). Teacher e-mail message strategies and students' willingness to communicate online. Journal of Applied Communication Research, 29, 54-70.

Yates, J., \& Orlikowski, W. J. (1992). Genres of organizational communication: A structurational approach to studying communication and media. Academy of Management Review, 17, 299-326.

Received September 15, 2003

Revised February 28, 2004

Accepted July 28, 2004 